\title{
THE INTEROSSEOUS MEMBRANE IN RADIO-ULNAR DISSOCIATION
}

\author{
ANDREW L. WALLACE, WILLIAM R. WALSH, \\ MIRIAM VAN ROOIJEN, JEFFERY S. HUGHES, DAVID H. SONNABEND
}

From the Prince of Wales Hospital, Sydney, Australia

\begin{abstract}
Tn severe forearm injuries, the diagnosis of disruption of the interosseous membrane is frequently delayed and sometimes missed, giving difficulties in the salvage of forearm stability.

We studied the structure and function of the interosseous membrane in 11 cadaver preparations, using mechanical and histological analysis. Seven of the specimens tested in uniaxial tension sustained a mid-substance tear of the central band of the membrane at a mean peak load of $1038 \pm 308 \mathrm{~N}$. The axial stiffness was $190 \pm 44 \mathrm{~N} / \mathrm{mm}$ with elongation to failure of $10.34 \pm 2.46 \mathrm{~mm}$. These results provide criteria for the evaluation of reconstructive methods.

A preliminary clinical investigation of the use of ultrasound suggests that this may be of value in the screening of patients with complex fractures of the forearm, and for investigating the natural history of tears of the interosseous membrane.
\end{abstract}

J Bone Joint Surg [Br] 1997;79-B:422-7.

Received 8 August 1996; Accepted after revision 31 October 1996

The management of severe fractures of the proximal radius is still a problem. When anatomical reconstruction of the fragments is not possible, primary excision of the radial head has been recommended for comminuted Mason typeIII fractures. ${ }^{1}$ The role of prosthetic replacement of the radial head is still controversial. ${ }^{2,3}$

Longitudinal dissociation of the radius and ulna is probably related to rupture of the interosseous membrane (IOM) at the time of injury. If the radial head is then excised, there may be proximal radial migration and subluxation of the

A. L. Wallace, PhD, FRACS, Senior Orthopaedic Registrar

W. R. Walsh, PhD, Director of Orthopaedic Research

J. S. Hughes, FRACS, Orthopaedic Surgeon

D. H. Sonnabend, BSc(Med), FRACS, Associate Professor

Department of Orthopaedic Surgery

M. van Rooijen, FRACR, Staff Specialist

Department of Radiology

Prince of Wales Hospital, High Street, Randwick, Sydney, New South Wales 2031, Australia.

Correspondence should be sent to Dr A. L. Wallace.

(C)1997 British Editorial Society of Bone and Joint Surgery 0301-620X/97/37142\$2.00 distal radio-ulnar joint (Fig. 1) as described by EssexLopresti and others. ${ }^{4,5}$ This has been regarded as an infrequent complication of fracture of the radial head, ${ }^{6}$ but the consequences of missing the diagnosis may be important. Trousdale et $\mathrm{al}^{7}$ reviewed 20 patients with radio-ulnar dissociation and found that only five had been diagnosed at first presentation, and the delay to diagnosis averaged seven years in the others. An objective scoring system showed that only $20 \%$ of patients with a delayed diagnosis of a ruptured IOM had a satisfactory outcome, despite attempts at salvage.

The site, extent and capacity for healing of the ruptured IOM are unknown, but an attempt at reconstruction using a graft from the palmaris longus tendon has recently been described by Hotchkiss. ${ }^{8}$ We report a mechanical, histological and ultrasound evaluation of the IOM, under controlled conditions. We aimed to investigate the pathomechanics, assess diagnostic methods and determine criteria for reconstructive procedures.

\section{MATERIALS AND METHODS}

Mechanical testing of structural properties. We studied the forearms of 11 human cadavers, ranging in age from 32 to 84 years. None had previous upper-limb injuries. The specimens were stored fresh frozen at $-20^{\circ} \mathrm{C}$ until testing, then thawed at room temperature. The skin, subcutaneous tissue and muscle were removed exposing the shafts of the radius and ulna with the linking IOM. The central thickened band of the IOM was easily identified, running from the radius proximally to the ulna distally. Approximately $75 \mathrm{~mm}$ of the diaphysis of each bone were resected together with the origin and insertion of the central band of the IOM. These samples were stored in a bath of $0.9 \% \mathrm{NaCl}$ at $25^{\circ} \mathrm{C}$.

We performed mechanical testing in uniaxial tension along the longitudinal axis of the forearm with an MTS 858 Mini-Bionix materials testing machine (MTS, Minneapolis, Minnesota). The specimens were fixed to custom-made jigs by pins placed through drillholes in the bones with a fixed gauge length of $50 \mathrm{~mm}$ for each specimen (Fig. 2). To reproduce the presumed clinical mechanism of the EssexLopresti lesion of the IOM, the radial jig was displaced longitudinally and proximally relative to the fixed ulnar jig 


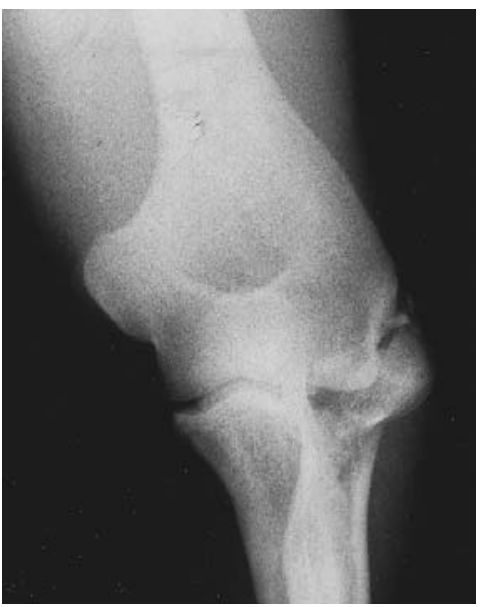

Fig. 1a

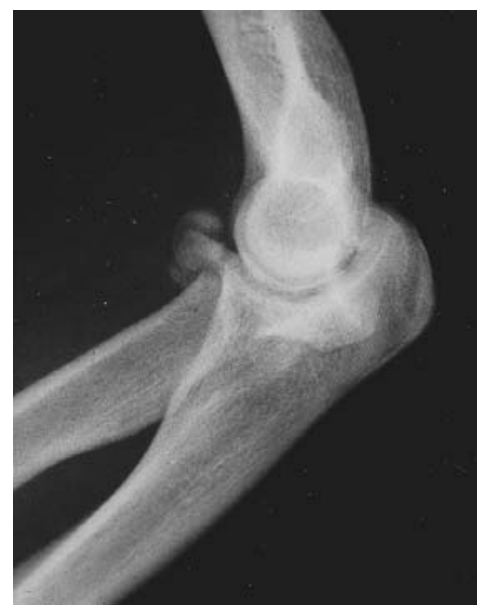

Fig. 1b

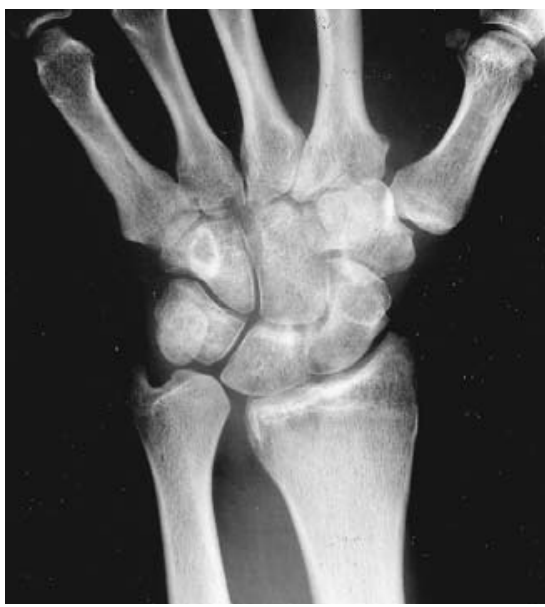

Fig. 1c

Anteroposterior (a) and lateral (b) views of a neglected comminuted fracture of the radial head. At three months the bone fragments were excised because of elbow pain. The patient then developed severe wrist pain due to proximal migration of the radius with subluxation of the distal radio-ulnar joint (c).

at a displacement rate of $50 \mathrm{~mm} / \mathrm{min}$. This is much slower than displacement during an injury, but allows more accurate determination of the components of the load-displacement curve, and is a recognised standard for testing bone-ligament-bone specimens. ${ }^{9}$ Load was plotted against displacement until failure, the site and mode of which were noted. We recorded the peak load and the elongation and energy absorbed at peak load. The tensile stiffness was determined from the linear portions of the plotted curves (Fig. 3).

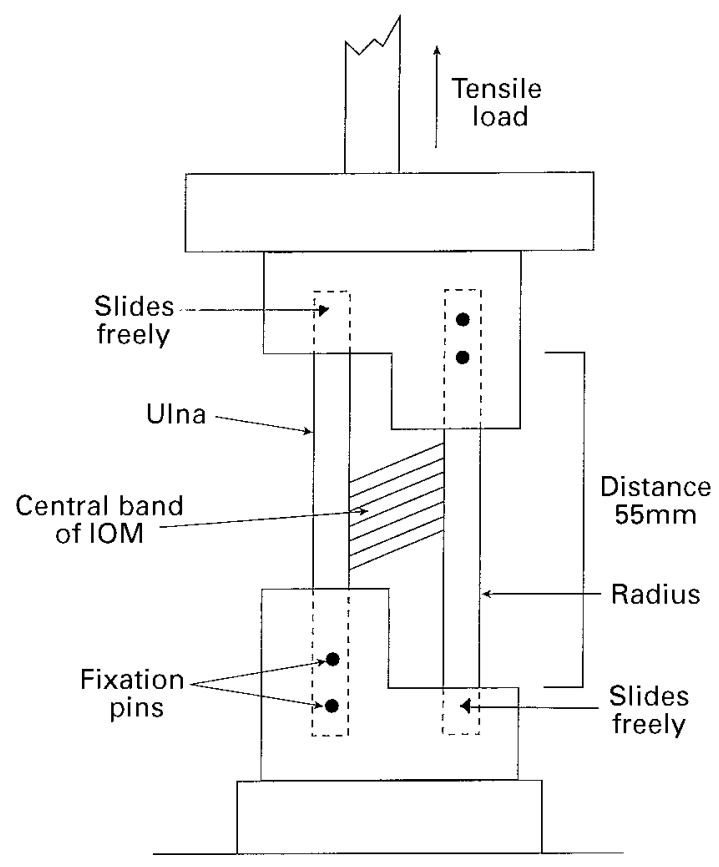

Fig. 2

Diagram of the test jig on an MTS materials testing machine. A tensile load was applied to the radius at $50 \mathrm{~mm} / \mathrm{min}$ until failure, either of the bone or the central band preparation.
Histological analysis. After mechanical testing, the failed samples were fixed in $10 \%$ phosphate-buffered formalin for 48 hours, decalcified in $0.5 \mathrm{M}$ EDTA at $\mathrm{pH} 7.5$, then dehydrated and embedded in paraffin. A series of transverse slices $5 \mu \mathrm{m}$ thick were cut across the long axis of the forearm and stained with haematoxylin and eosin or Masson trichrome. The sections were studied under an Olympus $\mathrm{BH} 2$ light microscope at 10, 50 and 200 times magnification.

Ultrasound imaging. One cadaver forearm including the elbow and wrist joints was thawed overnight at room temperature. A standard radiograph was made with the forearm in full supination, using two percutaneous hypodermic needles as proximal and distal reference markers. The distance between the two markers was measured directly on the radiograph to provide correction for magnification.



Fig. 3

An example of the load-displacement curve. There is a linear region before yield and failure, which in this case occurred through the midsubstance of the membrane. 
The forearm was gently warmed in an isotonic saline bath to $37^{\circ} \mathrm{C}$ and then imaged on an Acuson $128 \mathrm{XP} / 10$ ultrasonographic device (Acuson, Mountainview, California), using a $7 \mathrm{MHz}$ linear-array transducer transversely across its volar surface to locate the radius, ulna and IOM. The interosseous distance was measured at several levels in the forearm and compared with radiological measurements.

After ultrasonography of the intact IOM, a longitudinal incision was made over the dorsal surface of the forearm, which was still under saline to prevent air entering the tissues and producing artefacts during imaging. The extensor muscles were bluntly dissected from the dorsal surface of the IOM to allow a longitudinal incision through its midsubstance using a scalpel blade. The skin was closed by a watertight subcuticular non-absorbable suture, and ultrasound imaging was repeated from its volar surface.

\section{RESULTS}

Anatomy. The central band of the IOM was easily defined and had a thickness varying from 0.5 to $1.85 \mathrm{~mm}$, as measured with a micrometer. In all our specimens, the fibres were not in parallel alignment but fan-shaped, with differing relative fibre lengths and angles of origin from the radius to insertion on the ulna.

Failure in tension. During mechanical testing, four of the 11 specimens failed by fracture through an ulnar pin site before there was failure of the IOM. In the other seven specimens, an extensive mid-substance tear appeared, starting at the distal margin of the central band (Fig. 4). No specimen failed by avulsion from either bone.

The sigmoid shape of the load-displacement curve (Fig. 3) was a typical result of tensile testing of soft connective tissues at a moderate displacement rate. The mean peak load at mid-substance failure was $1038 \pm 308 \mathrm{~N}$, compared with $548 \pm 138 \mathrm{~N}$ for the bony failures through a pin site. The correspondingly lower energy absorbed before failure

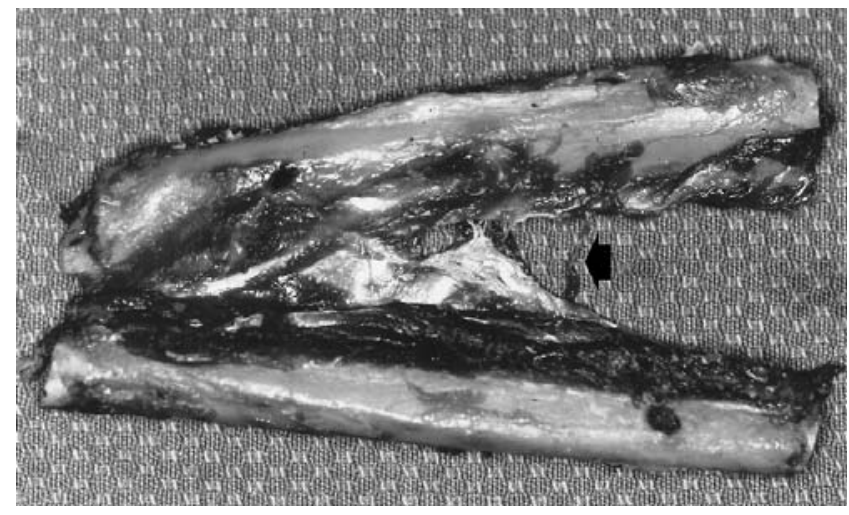

Fig. 4

Specimen of radius (above) and ulna after testing, showing an extensive mid-substance tear of the IOM, which originated at the distal margin of the central band (arrow).

through the ulna was probably due to the stress riser effect of the pin hole in relation to the geometry and quality of adjacent bone. It was still possible to plot load against displacement in all specimens, and the mean tensile stiffness, calculated from the linear portion of the curves, was $178 \pm 47 \mathrm{~N} / \mathrm{mm}$. Other data are summarised in Table I.

Histological examination. Histological sections of the IOM showed that the bases of the triangular-shaped insertion zones were thicker than the mid-substance, blending intimately with the periosteum at its margins (Fig. 5a). Higher magnification showed a thin collagenous sheet with layers of fibres arranged in parallel separated by interstitial layers running at a slightly oblique angle (Fig. 5b). These fibres were attached to the underlying lamellar bone through a 'tidemark' which defined a zone of mineralised fibrocartilage as described by Cooper and Misol. ${ }^{10}$ There were few vascular channels in the membrane itself, but skeletal muscle fibre bundles were prominent, in close apposition to the membrane.

Table I. Mechanical properties of radio-IOM-ulnar samples

\begin{tabular}{|c|c|c|c|c|c|}
\hline Sample & Mode of failure & $\begin{array}{l}\text { Peak load } \\
\text { (N) }\end{array}$ & $\begin{array}{l}\text { Tensile stiffness } \\
\text { (N/mm) }\end{array}$ & $\begin{array}{l}\text { Elongation at failure } \\
(\mathrm{mm})\end{array}$ & $\begin{array}{l}\text { Energy absorbed } \\
(\mathbf{J})\end{array}$ \\
\hline 1 & Tear & 1397 & 196.5 & 13.43 & 7.092 \\
\hline 2 & Tear & 1507 & 217.8 & 9.35 & 5.802 \\
\hline 3 & Tear & 934 & 272.8 & 11.22 & 4.597 \\
\hline 4 & Tear & 811 & 153.4 & 5.70 & 2.626 \\
\hline 5 & Tear & 651 & 151.4 & 12.14 & 2.077 \\
\hline 6 & Tear & 941 & 185.4 & 9.99 & 3.785 \\
\hline \multirow[t]{2}{*}{7} & Tear & 1027 & 153.3 & 10.57 & 3.694 \\
\hline & $\mathrm{n} \pm \mathrm{sD}$ & $1038 \pm 308$ & $190.0 \pm 44.5$ & $10.34 \pm 2.46$ & $4.239 \pm 1.755$ \\
\hline 8 & Fracture & 660 & 212.5 & 6.64 & 1.210 \\
\hline 9 & Fracture & 373 & 91.7 & 12.48 & 1.396 \\
\hline 10 & Fracture & 500 & 164.5 & 3.10 & 0.887 \\
\hline \multirow[t]{2}{*}{11} & Fracture & 658 & 157.6 & 4.17 & 1.757 \\
\hline & $\mathrm{n} \pm \mathrm{SD}$ & $548 \pm 138$ & $156.6 \pm 49.7$ & $6.60 \pm 4.19$ & $1.312 \pm 0.363$ \\
\hline
\end{tabular}




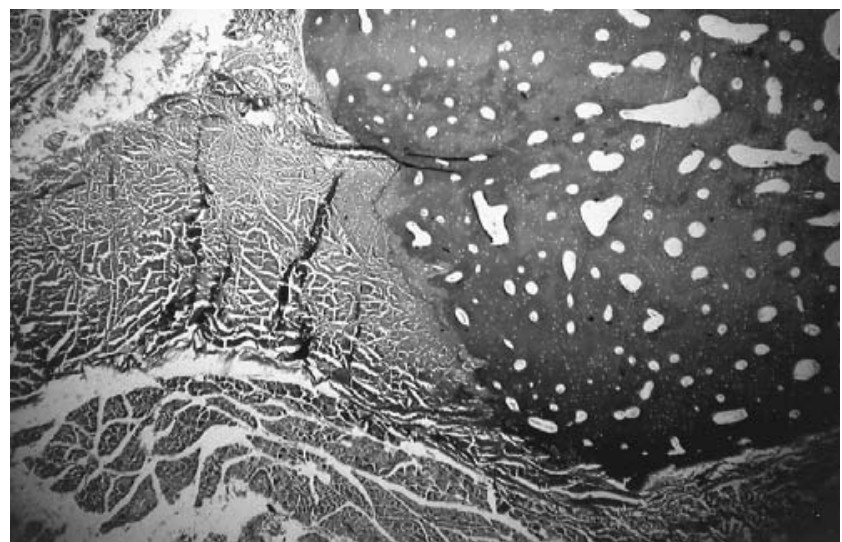

Fig. 5a

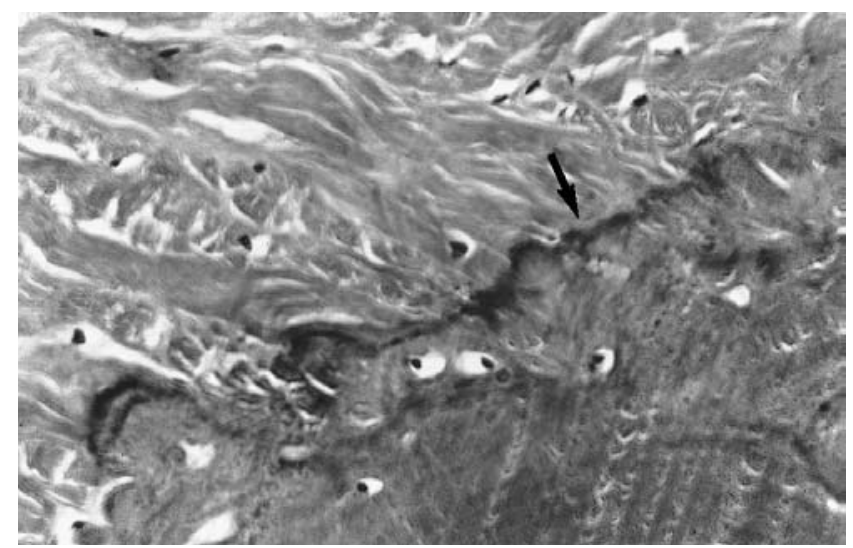

Fig. 5b

Transverse sections of the IOM showing its broad-based insertion on to the radius (Masson trichrome; $\times 27(a))$. At a higher magnification $(\times 108)(b)$ interleaved layers of collagen fibres are seen at oblique angles entering their insertion into bone through a zone of mineralised fibrocartilage (arrow).

Ultrasound studies. Ultrasound examination showed that the IOM was easily visualised as a highly echogenic structure, distinct from the adjacent muscles and lying between the echoic shadows of the radius and ulna. It was possible to trace the IOM proximally and distally and to determine its thickness at several points. The central band region was well-localised, with a thickness of 1.5 to $1.8 \mathrm{~mm}$ (Fig. 6a), in contrast to the thinner distal part which had a thickness of approximately $0.8 \mathrm{~mm}$ (Fig. 6b). These ultrasonic estimates confirmed those obtained by direct measurement of the dissected IOM.

Serial ultrasound measurements of the interosseous distance $(9.9$ to $14.1 \mathrm{~mm}$ ) were within $0.1 \mathrm{~mm}$ of the radiological estimates, showing a high level of agreement between techniques. After surgical incision of the IOM, the images confirmed this discontinuity at several levels (Fig. $6 c)$. The lesion was seen as a hypoechoic trace, which was even more apparent on continuous real-time images obtained during rotation of the forearm.

\section{DISCUSSION}

The longitudinal radio-ulnar dissociation described by Essex-Lopresti represents part of a complex fracturedislocation of the forearm. The critical element is failure of the central band of the IOM, but this may be masked until excision of the radial head. After this, there is instability of the whole radio-ulnar rotary mechanism, with relative apparent lengthening of the ulna at the wrist. Surgical procedures which attempt to restore neutral ulnar variance at the level of the distal radio-ulnar joint, ${ }^{11}$ fail to address this instability and may give poor results. Even when the IOM is intact, the replacement of the radial head by silicone rubber prostheses has been shown to be mechanically inadequate, with insufficient stiffness to withstand normal loads across the elbow without deformation. $^{3,12}$

Moore, Lester and Sarmiento ${ }^{13}$ studied the axial stability of the distal radio-ulnar joint in cadavers. They attemp-

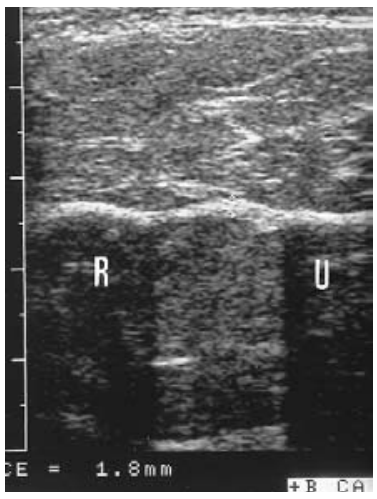

Fig. 6a

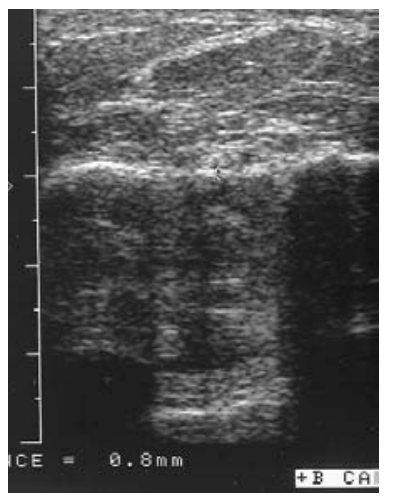

Fig. 6b

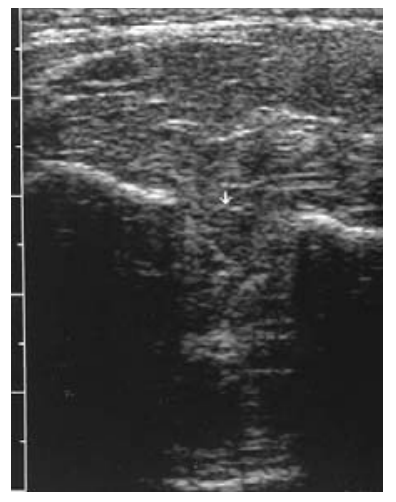

Fig. 6c

Transverse ultrasound images of the IOM in a cadaver forearm. Figure $6 a-$ The thick central band (markers) can be readily distinguished from the surrounding muscles and bones $(\mathrm{R}=$ radius, $\mathrm{U}=\mathrm{ulna})$. Figure $6 \mathrm{~b}-$ More distally, the membrane is thinner but is still visible. Figure $6 c-$ After division of the membrane, the defect is obvious (arrow). 
ted to reproduce Galeazzi lesions by creating elbow dislocations and diaphyseal fractures of both radius and ulna. They showed that osteotomy of the radius allowed axial movement of $3 \mathrm{~mm}$; the addition of division of the triangular fibrocartilage allowed movement of $6 \mathrm{~mm}$. An additional division of the central band of the IOM was associated with proximal migration of the radius of more than $10 \mathrm{~mm}$.

In the intact forearm, there are practical difficulties in reproducing these lesions. We isolated the central band with its radial and ulnar insertions and tested it separately as a distinct structure. The load-displacement curve which we obtained indicated that it behaved structurally as a strong ligament. The strength and stiffness values which we found broadly agreed with those recently reported by Boardman et al, ${ }^{14}$ although they used a smaller specimen of the central band alone and performed their tensile testing along the fibre axis, rather than the axis of the forearm.

The elongation of about $10 \mathrm{~mm}$ which we found before failure tends to support previous biomechanical studies based on the serial sectioning of soft-tissue structures in the forearm, ${ }^{13,15}$; these have associated an IOM tear with this amount of proximal radial migration. The loads causing mid-substance failure are of the same order of magnitude as those which were found by Frykman ${ }^{16}$ to result in distal radial fractures, and in the mid-range of those recently reported by Amis and Miller ${ }^{17}$ for fractures of the radial head. This implies that partial, low-grade tears or a degree of attenuation of the IOM may occur more often in forearm injuries than is generally recognised.

The diagnosis of a tear of the IOM is difficult in an acute clinical setting since pain arising from the distal radio-ulnar joint is commonly associated with proximal fractures even when the IOM is intact. ${ }^{18,19}$ Radiographs and intraoperative fluoroscopy have been used to assess resistance to axial stress, ${ }^{2}$ but these rely on relatively imprecise visual estimation of radial migration. MRI has also been used to demonstrate a mid-substance tear, ${ }^{8}$ but this is an expensive investigation and is not universally available. In the leg, ultrasound has been shown to be accurate and sensitive for the diagnosis of tears of the tibiofibular IOM associated with fractures about the ankle, ${ }^{20}$ but to our knowledge has not previously been used to image the IOM in the forearm. Our initial results indicate that, in association with conventional radiography, ultrasound may be useful in acute cases since it is relatively inexpensive, portable and can provide both static and dynamic images of the integrity of the ligament. We are now assessing this method prospectively.

Both the histological structure of the IOM and its attachments, and the pattern of disruption in experimental studies, make it likely that clinical failure is usually due to midsubstance tearing of the central band, rather than bony avulsion. The precise natural history of these complex injuries remains unknown and it may be that reconstruction of the radial head by internal fixation, or replacement by a prosthesis will prevent proximal migration of the radius and consequent instability and degeneration of the distal radioulnar joint. It seems possible that unless the IOM heals, its role in load transfer from wrist to elbow may be compromised. $^{21}$ There is also some evidence that healing with a relative change in the length of the IOM may affect forearm rotation. $^{22,23}$

There are theoretical advantages for primary repair, augmentation or reconstruction of the central band of the IOM in association with fixation of a fractured radius in the control of residual longitudinal instability. Replacement of the radial head with a prosthesis is essentially a salvage procedure. As yet, methods of repair of the IOM or its reconstruction have not been developed. Our biomechanical data along with those of Regan et $\mathrm{al}^{24}$ suggest that a graft of the palmaris longus tendon, shown to fail at approximately $350 \mathrm{~N}$, may not be strong enough to act as an effective substitute at high physiological loads. Further work is needed to document the natural history and healing potential of the IOM, and to suggest appropriate reconstruction. The goals in the treatment of forearm fractures with radio-ulnar dissociation are to restore anatomical relationships, and to provide fixation stable enough to allow early active mobilisation and rehabilitation.

No benefits in any form have been received or will be received from a commercial party related directly or indirectly to the subject of this article.

\section{REFERENCES}

1. Morrey BF. Current concepts in the treatment of fractures of the radial head, the olecranon, and the coronoid. J Bone Joint Surg 1995; 77-A:316-27.

2. Bennett JB. Radial head fractures: diagnosis and management. $J$ Should Elb Surg 1993;2:264-73.

3. Knight DJ, Rymaszewski LA, Amis AA, Miller JH. Primary replacement of the fractured radial head with a metal prosthesis. $J$ Bone Joint Surg 1993;75-B:572-6.

4. Essex-Lopresti P. Fractures of the radial head with distal radio-ulnar dislocation: report of 2 cases. J Bone Joint Surg [Br] 1951;33-B: 244-7.

5. McDougall A, White J. Subluxation of the inferior radio-ulnar joint complicating fracture of the radial head. J Bone Joint Surg [Br] 1957;39-B:278-87.

6. Davidson PA, Moseley JB, Tullos HS. Radial head fracture: a potentially complex injury. Clin Orthop 1993;297:224-30.

7. Trousdale RT, Amadio PC, Cooney WP, Morrey BF. Radial ulnar dissociation: a review of 20 cases. J Bone Joint Surg [Am] 1992; 74-A:1486-97.

8. Hotchkiss RN. Injuries to the interosseous ligament of the forearm. Hand Clin 1994;10:391-8.

9. Woo SL, Peterson RH, Ohland KJ, Sites TJ, Danto MI. The effects of strain rate on the properties of the medial collateral ligament in skeletally immature and mature rabbits: a biomechanical and histological study. J Orthop Res 1990;8:712-21.

10. Cooper RR, Misol S. Tendon and ligament insertion: a light and electron microscopic study. J Bone Joint Surg 1970;52-A:1-20.

11. Sauvé L, Kapandji M. Nouvelle technique de traitement chirurgical des luxations récidivantes isolées de l'extrémité inférieure du cubitus. J de Chir 1936;47:589-94.

12. Hotchkiss RN, An K-N, Sowa DT, Basta S, Weiland AJ. An anatomic and mechanical study of the interosseous membrane of the forearm: pathomechanics of proximal migration of the radius. $J$ Hand Surg [Am] 1989;14:256-61.

13. Moore TM, Lester DK, Sarmiento A. The stabilizing effect of softtissue constraints in artificial Galeazzi fractures. Clin Orthop 1985; 194:189-94. 
14. Boardman ND, Pfaeffle HJ, Xu J, Grewal R, Tomaino MM, Herndon JH. Tensile properties of the interosseous membrane of the human forearm. Trans Orth Res Soc 1995;20:629.

15. Schneiderman G, Meldrum RD, Bloebaum RD, Tarr R, Sarmiento A. The interosseous membrane of the forearm: structure and its role in Galeazzi fractures. J Trauma 1993;35:879-85.

16. Frykman G. Fracture of the distal radius including sequelae-shoulderhand-finger syndrome, disturbance in the distal radio-ulnar joint and impairment of nerve function: a clinical and experimental study. Acta Orthop Scand Suppl 1967;Suppl 108.

17. Amis AA, Miller JH. The mechanics of elbow fractures: an investigation using impact tests in vitro. Injury 1995;26:163-8.

18. Taylor TKF, O'Connor BT. The effect upon the inferior radio-ulnar joint of excision of the head of the radius in adults. J Bone Joint Surg [Br] 1964;46-B:83-8.

19. Morrey BF, Chao EY, Hui FC. Biomechanical study of the elbow following excision of the radial head. J Bone Joint Surg [Am] 1979; 61-A:63-8
20. Christodoulou G, Korovessis P, Giarmenitis S, Dimopoulos P, Sdougos G. The use of sonography for evaluation of the integrity and healing process of the tibiofibular interosseous membrane in ankle fractures. J Orthop Trauma 1995;9:98-106.

21. Rabinowitz RS, Light TR, Havey RM, et al. The role of the interosseous membrane and triangular fibrocartilage complex in forearm stability. J Hand Surg Am 1994;19::385-93.

22. Matthews LS, Kaufer H, Garver DF, Sonstegard DA. The effect on supination-pronation of angular malalignment of fractures of both bones of the forearm: an experimental study. J Bone Joint Surg [Am] 1982;64-A:14-7.

23. Tarr RT, Garfinkel AI, Sarmiento A. The effects of angular and rotational deformities of both bones of the forearm: an in vitro study. J Bone Joint Surg [Am] 1984;66-A:65-70.

24. Regan WD, Korinek SL, Morrey BF, An K-N. Biomechanical study of the ligaments around the elbow joint. Clin Orthop 1991;271: $170-9$ 